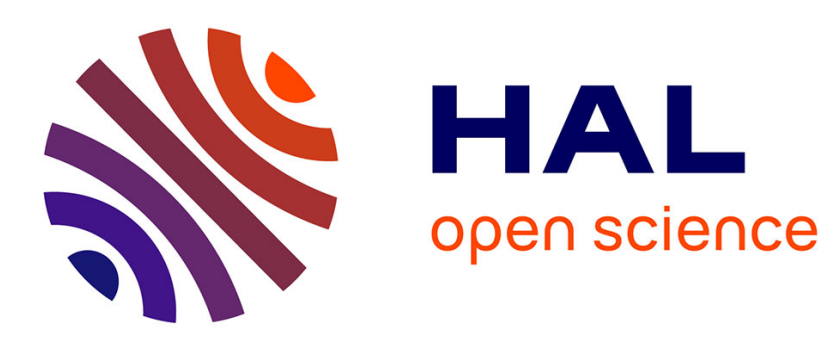

\title{
Multiphase and multiscale approaches for modelling the injection of textured moulds
}

Rebecca Nakhoul, Patrice Laure, Luisa Silva, Michel Vincent

\section{To cite this version:}

Rebecca Nakhoul, Patrice Laure, Luisa Silva, Michel Vincent. Multiphase and multiscale approaches for modelling the injection of textured moulds. ESAFORM 2016, Apr 2016, Nantes, France. pp.20008, 10.1063/1.4963412 . hal-01385478

\section{HAL Id: hal-01385478 \\ https://hal.science/hal-01385478}

Submitted on 21 Oct 2016

HAL is a multi-disciplinary open access archive for the deposit and dissemination of scientific research documents, whether they are published or not. The documents may come from teaching and research institutions in France or abroad, or from public or private research centers.
L'archive ouverte pluridisciplinaire HAL, est destinée au dépôt et à la diffusion de documents scientifiques de niveau recherche, publiés ou non, émanant des établissements d'enseignement et de recherche français ou étrangers, des laboratoires publics ou privés. 


\title{
Multiphase and Multiscale Approaches for Modelling the injection of textured moulds
}

\author{
Rebecca Nakhoul $^{1, \mathrm{~b})}$, Patrice Laure ${ }^{1,2, \mathrm{a})}$, Luisa Silva ${ }^{3, \mathrm{c})}$ and Michel Vincent ${ }^{1, \mathrm{~d})}$ \\ ${ }^{1}$ CEMEF - MINES ParisTech, Sophia-Antipolis, France. \\ ${ }^{2} J A D$ - université de Nice Sophia-Antipolis , Nice, France \\ ${ }^{3}$ ICI - Ecole Centrale de Nantes, France \\ ${ }^{a)}$ Corresponding author: Patrice.Laure@unice.fr \\ ${ }^{b)}$ rebecca.nakhoul@mines-paristech.fr \\ c)luisa.rocha-da-silva@ec-nantes.fr \\ d) michel.vincent@mines-paristech.fr
}

\begin{abstract}
Micro-injection moulding is frequently used for the mass production of devices in micro-medical technologies, microoptics and micro-mechanics. This work focuses mainly on offering numerical tools to model the injection of micro-textured moulds. Such tools can predict the different filling scenarios of the micro-details and consequently offer optimal operating conditions (mould and melt temperatures, melt flow, stresses, etc.) to analyse the final part quality. To do so, a full Eulerian approach is used to model the injection of textured moulds at both the macroscopic and microscopic scales as usual industrial software cannot handle the filling of micro details. Since heat transfers with the mould are very relevant due to high cooling rates, the coupling between microand macro- simulations is primordial to insure a complete and accurate representation of textured mould injection.
\end{abstract}

\section{Introduction}

A micro-moulding process consists on transferring micro details of micro-structured mould to products having a shear-thinning behaviour in their liquid phases. By definition, a micro moulded part can be either a piece weighing less than $1 \mathrm{mg}$ or a part exhibiting micro details with a wall thickness less than $100 \mu \mathrm{m}$. In the last decades, microinjection moulding was rated as the most used micro-moulding technique. It presents a wide range of applications like micro-mechanics, micro-optics, micro-medical and micro-chemical applications, with good cost-effectiveness ratio for mass production.

Modelling Micro-Injection moulding presents a lot of challenges as it can be difficult to scale down the macroscopic physical properties [2, 3, 4]. In addition, several factor/phenomena commonly neglected in macroscopic moulding simulations have significant impact on micro-injection accuracy [5] due to the greater surface-volume ratio. Some of these neglected components are the surface tension, the surface roughness, the heating of the melt by viscous friction and the fast cooling due to the thin wall thickness [6].

A multiphase Eulerian approach is adopted where the different phases are described implicitly using a Level set method [10]. The global properties are determined from local ones using mixture laws. One mesh is used all over the domain. It is anisotropically refined relocating nodes to zones where information is highly needed [9]. The adopted strategy to pass from a macroscopic to a microscopic scale is described in the next sections.

\section{Macroscopic computations using industrial software}

Using the commercial software Rem3D® [7], we model the injection moulding on the macroscopic scale. The mould itself is represented by its internal boundaries on which both temperature and velocities are imposed. To clarify the adopted procedure, we begin by looking at an example at the macroscopic scale. The mould cavity illustrated in Figure 1 is injected by a viscous shear-thinning material (PolyPropylene, PP-PRO-FAX PD702 in Cadmould database) with 
a flow rate reaching $Q=25 \mathrm{~cm}^{3} / \mathrm{s}$. Its initial temperature is $T_{0}=205^{\circ} \mathrm{C}$. The mould surface has micro cavities in the central zone which are not detected in the macroscopic software due to mesh limitations. The Micro cavities have a depth of $10 \mu \mathrm{m}$ and a length of $10 \mu \mathrm{m}$. The mould temperature does not vary with time and is denoted $T_{m}=35^{\circ} C$. It is imposed directly on the cavity boundaries. The melt follows a Carreau-Yasuda law where the thermo-dependency is defined by a William-Landel-Ferry model.

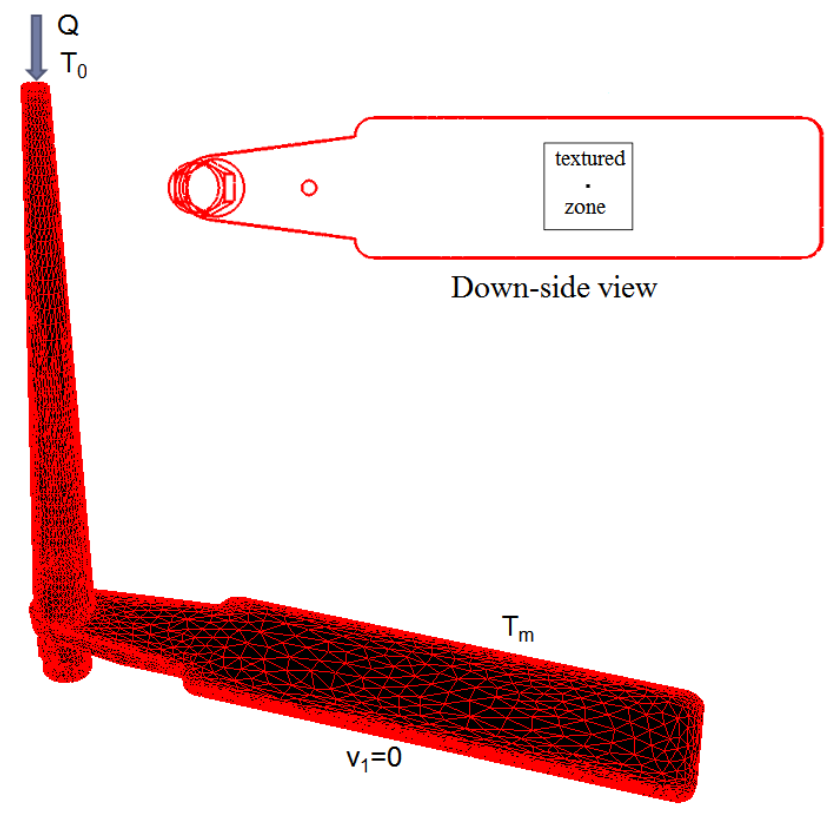

FIGURE 1. The cavity used in computations: $50 \mathrm{~mm}$ by $15 \mathrm{~mm}$ piece with a thickness of $1 \mathrm{~mm}$ with a textured zone begining at $21 \mathrm{~mm}$ from the end wall

The evolution of the melt, the temperature and velocity are tracked in time. The melt arrives at the beginning of the textured zone at $t_{1}=0.0725 \mathrm{~s}$, at the end of this zone at $t_{2}=0.08 \mathrm{~s}$. The cavity is filled in approximately $t_{3}=0.1 \mathrm{~s}$. The temperature is hot in the core reaching $210^{\circ} \mathrm{C}$ and is cool on the skin due to the mould temperature $\left(35^{\circ} \mathrm{C}\right)$. The temperature and velocity plotted on a transverse section are shown in Figures 2 . The values of temperature and horizontal velocity remain constant and are equal to $210^{\circ} \mathrm{C}$ and $2.5 \mathrm{~m} / \mathrm{s}$. Except close to the lateral walls, the flow is essentially 2D in the $x y$ plane ( $x$ being the streamline direction, $y$ being aligned along the thickness). Therefore, the flow motion and temperature profile would be obtained by a two dimensional computations. This is why a two dimensional computations will be performed in the sequel with the data collected before the textured zone.

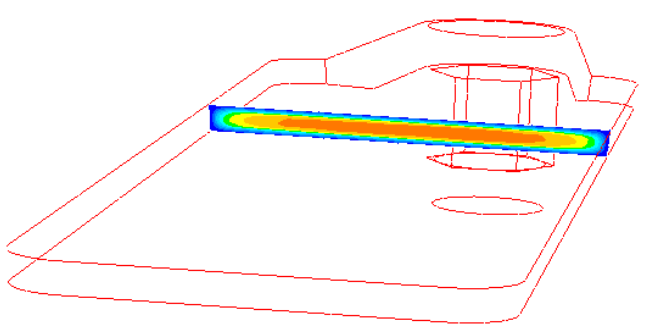

(b)
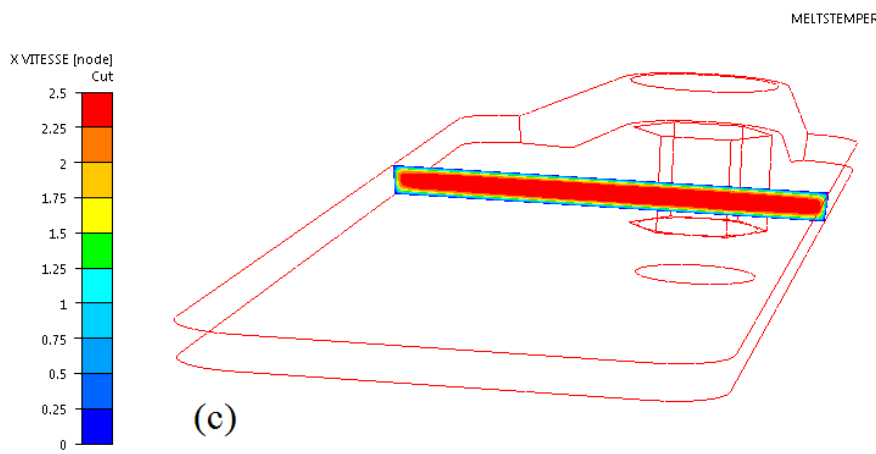

(c)

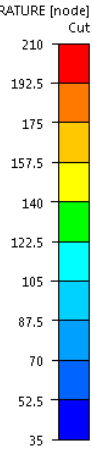

FIGURE 2. The velocity and temperature in a transverse section at $t=0.0725 \mathrm{~s}$. 


\section{Multiphase Computations}

The depth of textured zone is around $10 \mu \mathrm{m}$ or 100 times smaller than the cavity thickness and thus cannot be detected using common industrial software. The micro details studied here are uniform slots in the transverse direction (perpendicular to the flow direction) positioned in the center of the bottom side. Therefore two dimensional computations can be enough to describe the melt behaviour in the textured zone.

They are then fed to the multiphase model as illustrated in Figure 3. The main parameter describing the lowest levels is the characteristic length $L_{r e f}$ which gives the thickness of the computational domain equally divided between the mould and the cavity. In practice, we choose two characteristics lengths $L_{r e f}$ equal to $1 \mathrm{~mm}$ and $0.1 \mathrm{~mm}$ and boundary conditions are recovered from previous computations.

- $\quad L_{\text {ref }}=1 \mathrm{~mm}$ (a macroscopic multiphase computation), the flow motion corresponds roughly to a half Poiseuille flow. The thermal transfers are properly represented. The upper velocity and initial temperature are deduced from Rem $3 \mathrm{D} \AA$ computations.

- $\quad L_{r e f}=0.1 \mathrm{~mm}$ (a microscopic multiphase computation), the flow motion corresponds roughly to a Couette flow, and the cavity filling is analysed.

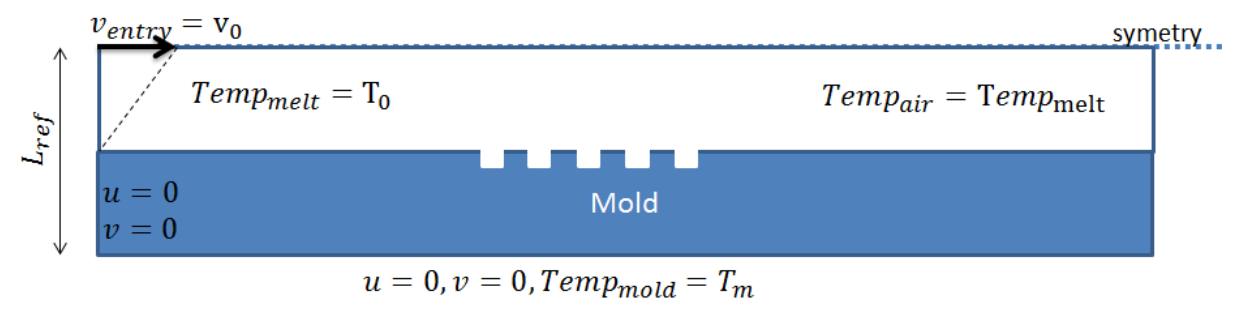

FIGURE 3. The 2D scheme used for microscopic modeling.

It is recommended to use scaled equations in this framework. Not only zooming-in is simpler (by modifying $L_{r e f}$ ) but also computing cavity filling (needing very small time steps) is possible. They enable us to work with constant fictitious time steps (namely $\left.\Delta t_{\text {fict }}\right)$ which corresponds to very small real time steps $\left(\Delta t=\Delta t_{\text {fict }} L_{\text {ref }} / V_{\text {ref }}\right)$.

\section{Scaled equations and non-flow criterion}

The computations are performed on a rectangular domain with an unitary height. Therefore, we choose to scaled the momentum and heat equations by taking $L_{r e f}, V_{r e f}$, a melt diffusivity $k_{\text {melt }}$ and a reference viscosity $\eta_{0}$ for scaling factors:

$$
\begin{aligned}
\frac{\rho V_{\mathrm{ref}} L_{\mathrm{ref}}}{\eta_{0}}\left(\partial_{t} v+v \cdot \nabla v\right) & =\nabla \cdot\left(2 \frac{\eta}{\eta_{0}} \epsilon(v)\right)-\nabla p \\
\nabla \cdot v & =0 \\
\frac{\rho C_{p} L_{\mathrm{ref}} V_{\mathrm{ref}}}{k_{\mathrm{melt}}}\left(\frac{\partial T}{\partial t}+v \nabla T\right)-\frac{k}{k_{\mathrm{melt}}} \Delta T & =\frac{\eta_{0} V_{\mathrm{ref}}^{2}}{k_{\mathrm{melt}}}\left(2 \frac{\eta}{\eta_{0}} \epsilon(v): \epsilon(v)\right)
\end{aligned}
$$

where $v, p, T$ and $\epsilon(v)$ are the velocity, the pressure, the temperature and shear rate tensor respectively. The temperature dependence is usually described by Arrhenius or WLF laws. For simplicity, the Cadmould material database proposes that the PP behaviour is approximated by an amorphous polymer (the crystallisation is not taken into account) and its dependence is given a modification of WLF relationship which will depend on two temperatures $T_{\text {ref }}$ and $T_{s}$. The temperature $T_{\text {ref }}$ is the temperature chosen within the range of rheological measurements and the temperature $T_{s}$ is a temperature used to fit these measurements (namely $T_{\text {ref }}=205^{\circ} C$ and $T_{s}=62.5^{\circ} C$ for the PP). The shift factor has expression:

$$
\log a_{T}=-\left[\frac{C_{1}\left(T-T_{s}\right)}{C_{2}+\left(T-T_{s}\right)}\right]+\left[\frac{C_{1}\left(T_{\mathrm{ref}}-T_{s}\right)}{C_{2}+\left(T_{\mathrm{ref}}-T_{s}\right)}\right]
$$


where $C_{1}$ and $C_{2}$ are universal constants obtained by averaging values for several polymers $\left(C_{1}=8.86, C_{2}=101.6\right.$ in our study). As a consequence, the polymer should no longer progress as the temperature tends towards $T_{s}$.

In our multi-domain approach [10], the viscosities for mould and air are chosen with respect to the melt viscosity by taking into account the following constraints: for the numerical procedure, the matrix conditioning is better if the ratio between maximal and minimal viscosities through the computational domain is less than $10^{10}$; the mould viscosity has to be important enough in order to have an almost null velocity inside the mould; the air viscosity should be small enough to guarantee the fountain flow at the air/melt interface. Thus, a non-flow criterion based on the high values of viscosity when the temperature is close to the solidification temperature has been already tested [8] and gives raise to ill conditioned matrix. As this criterion is especially crucial when modelling micro-cavity filling, we have checked another method based on a penalty method which can ensure no flow motion for a given temperature $T_{p s}$.

The numerical method used to solve the above equations is based on the use of a stable mixed formulation, which consists of continuous piecewise linear functions enriched with a bubble function for the velocity and piecewise linear functions for the pressure. A brief presentation of our mixed finite element method is presented in [10]. We can explain here how to impose the no-flow condition by penalty method. The weak formulation of Navier-Stokes equations is written on a suitable trial functional spaces $Q$ and $\mathcal{V}$ and reads:

find $(\mathbf{u}, p) \in \mathcal{V} \times Q$ such that

$$
\begin{gathered}
\int_{\Omega} \rho d_{t} \mathbf{u} \cdot \mathbf{v}+\int_{\Omega} 2 \eta \epsilon(\mathbf{u}): \epsilon(\mathbf{v}) d \Omega-\int_{\Omega} p \nabla \cdot \mathbf{v} d \Omega= \\
\int_{\Omega} A_{P}(T) \mathbf{u} \cdot \mathbf{v} d \Omega+\int_{\Omega} \delta_{\Gamma}[[\sigma \cdot \mathbf{n}]] \cdot \mathbf{v} d \Omega \\
\int_{\Omega} \nabla \cdot \mathbf{u} q d \Omega=0
\end{gathered}
$$

where the penalty factor $A_{p}(T)$ is defined:

$$
A_{p}(T)= \begin{cases}0 & \text { if } T \geq T_{p s} \\ 10^{6} \max \left(\eta_{\text {melt }}\right) & \text { if } T<T_{p s}\end{cases}
$$

and $[[\sigma \cdot \mathbf{n}]]$ is the jump of the normal stress at the interface $\Gamma$, defined implicitly by $T=T_{p s}\left(\delta_{\Gamma}\right.$ being the Dirac function associated to this interface). This latter term is added as the vanishing condition on the velocity and it is not compatible with the continuity of the normal stress involved in the classical Finite Element formulation.

\section{Multiphase Computations at Macroscale: $L_{r e f}=1 \mathrm{~mm}$}

In the entrance, we impose a Poiseuille flow conserving the same flow rate $\left(Q=2.510^{-5} / 0.015 / 2=0.008333 \mathrm{~m}^{2} / \mathrm{s}\right)$. Thus, the reference velocity $V_{\text {ref }}$ is equal to $Q / L_{\text {ref }}$. At the entrance of the cavity, a temperature profile is imposed: first the contact temperature $T_{i}$ between the mould and melt for a purely conductive heat transfer is computed thanks to an analytic formula [1] by taking $T_{\text {mould }}=35^{\circ} \mathrm{C}$ and $T_{\text {melt }}=210^{\circ} \mathrm{C}$; then a constant temperature $T_{\text {melt }}$ is put inside the melt expect in the thermal boundary layer at the mould/melt interface (the temperature smoothness between $T_{\text {melt }}$ and $T_{i}$ is made with an erf function); finally a linear profile between $T_{m}$ and $T_{i}$ is imposed inside the mould.

The results are presented in Figures 4 where the mould/melt interface is located at $y=0$. For $y=-0.5$ (scaled vertical coordinate), the temperature is equal to the mould temperature $35^{\circ} \mathrm{C}$. As for $y=0.5$, it is equal to the melt temperature $205^{\circ} \mathrm{C}$. The interface temperature corresponding to $y=0$ is equal to $47.8^{\circ} \mathrm{C}$.

Studying the thermal transfers in the mould is achievable on this scale but the cavities are hardly visible. Thus, tracking the textured zone filling is impossible. To overcome this point, we take next $L_{\text {ref }}=0.1 \mathrm{~mm}$ as explained earlier. This value seems suitable since the size of thermal boundary layer above the mould is around $0.05 \mathrm{~mm}$.

\section{Multiphase Computations at Miscroscale: $L_{r e f}=0.1 \mathrm{~mm}$}

Taking $L_{r e f}=0.1 \mathrm{~mm}$, it is equivalent to zooming 10 times. The boundary and initial conditions are recovered from the previous computation for $L_{r e f}=1 \mathrm{~mm}$. The melt initial velocity and temperature are respectively equal to $0.56 \mathrm{~m} / \mathrm{s}$ and $205^{\circ} \mathrm{C}$ (for $y=0.05 \mathrm{~mm}$ or $y=0.55$ (normalized coordinates with $L_{\text {ref }}=1 \mathrm{~mm}$ ) ). The new mould temperature is equal to $39.85^{\circ} \mathrm{C}$ for $y=-0.05 \mathrm{~mm}$. This microscopic geometry allows a better observation of both the mould 


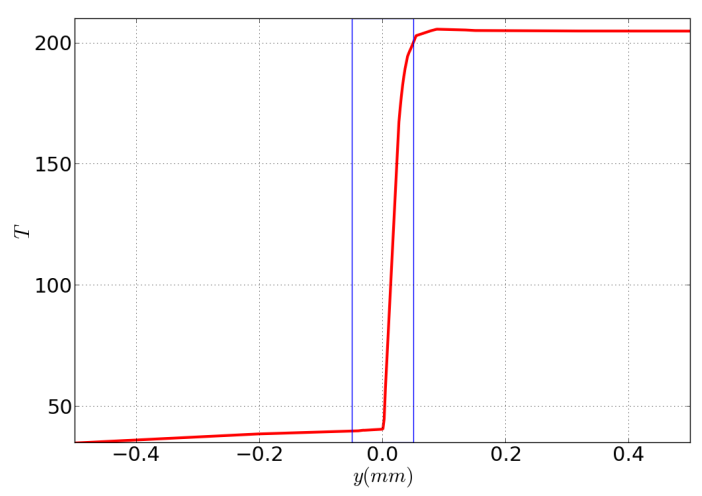

(a)

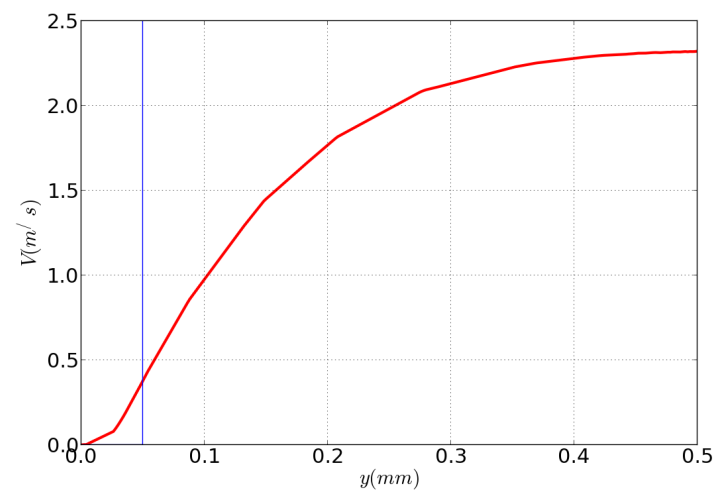

(b)

FIGURE 4. The temperature and velocity plotted on the transverse section for $L_{r e f}=1 \mathrm{~mm}$ and $T_{m}=35^{\circ} \mathrm{C}$. The thermal boundary layer studied at microscale is delimited by vertical blue lines.

and the textured zone. The non-flow criterion is activated by the penalized solidification temperature $T_{p s}$. Figures 5 illustrate different filling and it is shown that the final position of the level set representing the flow front depends on the solidification temperature. The corresponding filling rates are given in Table 1.

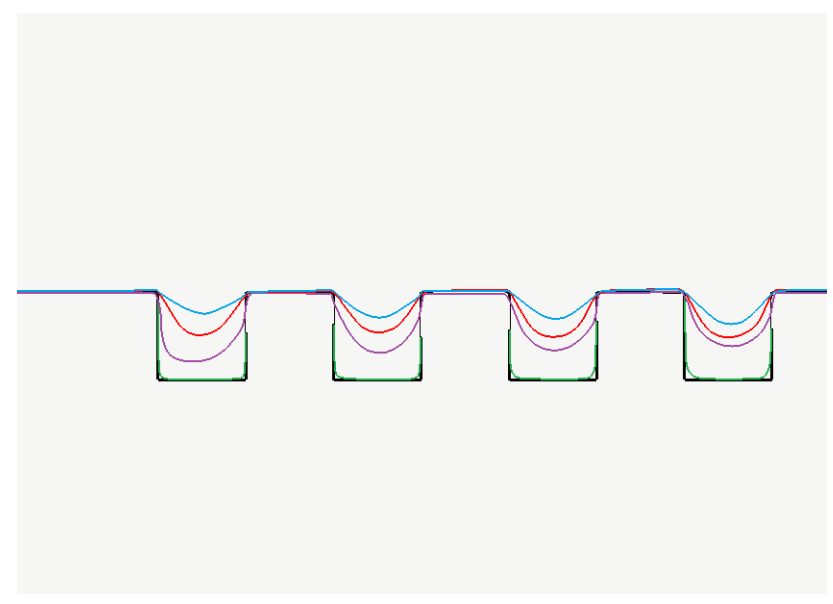

FIGURE 5. Cavities filling for $L_{\text {ref }}=0.1 \mathrm{~mm}$ and $t=0.1 \mathrm{~s}$ for various values of $T_{s}=40$ (green), 50 (pink), 80 (red), 100 (blue) ${ }^{\circ} \mathrm{C}$ by using a penalization method.

TABLE 1. Filling rate (Surface filling/Surface of holes) as a function of the freezing temperature $T_{p s}$.

\begin{tabular}{c|cccc}
$T_{p s}$ & 40 & 50 & 80 & 100 \\
filling rate & 0.99 & 0.53 & 0.25 & 0.084
\end{tabular}

The choice of a suitable solidification temperature $T_{p s}$ which can depend on the shear rate can be made by comparing experimental and numerical filling rates. 


\section{REFERENCES}

[1] Agassant J.-F., Avenas P., Sergent J.-.P, Vergnes B. and Vincent M. (2014), Mise en forme des polymres : Approche thermomcanique de la plasturgie, Lavoisier 4ème Edition.

[2] Tolinski M. (2005), Macro challenges in micromolding, Plast. Eng. 61(9):1416

[3] Attia U.-M., Marson S and Alcock J R (2009), Micro-injection moulding of polymer microfluidic devices, Microfluidics and Nanofluidics, 7:1-28

[4] Yang C., Yin X.-H., and Cheng G.-M. (2013), Microinjection molding of microsystem components: new aspects in improving performance, Journal of Micromechanics and Microengineering, 23:093001

[5] Hill S., Kamper K., Dasbach U., Dopper J., Ehrfeld W. and Kaupert M. (1995), An investigation of computer modelling for microinjection moulding, Proceedings of microsym'95

[6] Yu L., Lee L. and Koelling K. (2004), Flow and heat transfer simulation of injection molding with microstructures, Polym Eng Sci, 44(10):18661876

[7] Francois G., Ville L., Silva L. and Vincent M. (2013), Multi Criteria Adaptive Meshing for Polymers Processing in Rem3D®, Key Engineering Materials, 554-557, 1649-1657

[8] Nakhoul R., Laure P., Silva L. and Vincent M. (2015), Modeling the injection of textured molds, 22ème Congrès Fran cais de Mécanique (Lyon)

[9] Coupez T. (2011), Metric construction by length distribution tensor and edge based error for anisotropic adaptive meshing, Journal of Computational Physics, 230(7):2391-2405

[10] Coupez T., Digonnet H., Hachem E., Laure P., Silva L. and Valette R. (2013), Multidomain Finite Element Computations, in Arbitrary Lagrangian-Eulerian and FluidStructure Interaction, John Wiley \& Sons, 221-290

[11] Ville L., Silva L. and Coupez T. (2011), Convected level set method for the numerical simulation of fluid buckling, International Journal for Numerical Methods in Fluids, 66(3):324344 